\title{
Selling stem cell 'treatments' as research: prospective customer perspectives from crowdfunding campaigns
}

\author{
Jeremy Snyder ${ }^{*, 1}$ \& Leigh Turner ${ }^{2}$ \\ ${ }^{1}$ Faculty of Health Sciences, Simon Fraser University, 8888 University Drive, Burnaby, BC V5A 1S6, Canada \\ ${ }^{2}$ Center for Bioethics, University of Minnesota, N-302 Boyn HS, 410 Church Street SE, Minneapolis, MN 55455, USA \\ *Author for correspondence: Tel.: +1 778782 3258; Jcs12@sfu.ca
}

\begin{abstract}
Aim: To better understand how prospective customers interpret claims of businesses marketing unproven stem cell products that they are engaging in research activities. Materials \& methods: The authors examined 408 crowdfunding campaigns for unproven stem cell interventions for references to research activities. Results: The authors identified three overarching themes: research as a signifier of scientific credibility; the experimental nature of stem cells as a rationale for noncoverage by insurers; and contributing to the advancement of science by engaging in research. Conclusion: The NIH, US FDA and others should be concerned about being co-opted to misrepresent the nature of these businesses' activities. Efforts are also needed to better inform those considering purchasing unproven stem cell interventions about their relationship to legitimate research.
\end{abstract}

First draft submitted: 22 January 2018; Accepted for publication: 14 May 2018; Published online: 9 July 2018

Keywords: crowdfunding • funding $\bullet$ industry $\bullet$ patient perspectives $\bullet$ policy $\bullet$ social media $\bullet$ stem cell research $\bullet$ unproven interventions

A global marketplace featuring hundreds of businesses selling unproven stem cell interventions emerged over the last decade. Early research examining this marketplace focused on patients traveling to clinics situated in such countries as China, India, Russia and the Ukraine [1-5]. Clinics selling unproven stem cell interventions were initially thought to be located largely in jurisdictions with regulatory loopholes or under-resourced law enforcement agencies [6-8]. More recently, empirical studies of online direct-to-consumer marketing by businesses selling 'stem cell treatments' have documented proliferation of such clinics in Australia, Japan and the USA [9-15]. Once assumed to have stringent laws and effective regulatory agencies governing the processing, sale and distribution of stem cell products, these countries have witnessed the development of domestic direct-to-consumer markets consisting of companies using powerful advertising claims to sell stem cell products lacking conclusive evidence of safety and efficacy. National agencies such as the US FDA and Australia's Therapeutic Goods Administration have struggled to regulate such markets.

Premature commercialization of putative 'stem cell therapies' raises a host of ethical issues and scientific concerns, and in many cases prompts troubling questions about whether particular businesses are compliant with all applicable laws and regulations [16-24]. To date, researchers have identified numerous marketing techniques and tokens of legitimacy' businesses use to promote unproven stem cell products and make themselves appear credible and trustworthy [25]. Such companies are adept at using the trappings of science in their marketing rhetoric [26]. Early examples of such 'tokens' involved businesses linking or otherwise referring to preclinical or clinical research conducted by scientists at reputable institutions and then claiming that such studies support direct-to-consumer advertising of purported 'stem cell treatments'. Representative 'tokens of legitimacy' now include promoting 'patientfunded' or 'selfpay' studies, obtaining institutional review board approval for such studies, claiming government agencies such as the NIH or FDA have reviewed, funded, registered or approved such studies, and registering studies on ClinicalTrials.gov $[10,25,27]$. 
'Pay-to-participate' clinical studies have been the subject of considerable criticism for, in many instances, failing to meet contemporary ethical, scientific and legal standards for the conduct of research involving human participants [28-30]. Although such critiques have identified major problems in the design and conduct of such studies and exposed how companies use the appearance of conducting credible clinical research to attract prospective customers, to date researchers have paid little attention to how the tokens of scientific legitimacy associated with pay-to-participate stem cell studies have been understood and used by individuals seeking stem cell treatments for various indications. Although not all companies selling unproven stem cell interventions claim to be engaged in the conduct of clinical research, some do.

To better understand how representations of these businesses as being actively engaged in clinical research activities are understood and used to motivate purchase of their services, we examined crowdfunding campaigns for unproven stem cell interventions. Crowdfunding campaigns take advantage of social networks to raise money for a business or for personal use. Personal crowdfunding campaigns can be started by the intended recipient of the funding or a third party - often a family member or friend. They are hosted by crowdfunding platforms that guide the creation of the campaigns, help disseminate them via Facebook, Twitter and other social media, and process donations. The major personal crowdfunding platforms are run by American companies and dominated by US-based users, but their use is increasingly common across the English-speaking world [31]. The largest crowdfunding platform for medical treatment, GoFundMe, has raised over US $\$ 5$ billion since 2010 [32], followed by YouCaring with $\$ 900$ million for medical treatment since 2011 [33]. Recently, GoFundMe acquired YouCaring, creating a combined company that dominates social crowdfunding [31]. Specifically, we examined campaigns in which individuals were depicted as seeking donations with the intention of using such funding to access stem cell interventions provided in the context of what they understood to be credible clinical research. These campaigns typically include information about the medical and financial needs of the recipient and a narrative about how the funds will be spent and why the recipient is deserving of help [34]. Thus, these crowdfunding campaigns provide a wealth of information concerning how individuals seeking unproven stem cell interventions interpret these tokens of legitimacy and how they communicate signs of credibility to friends, family and other community members. Such campaigns provide researchers with an opportunity to better understand how businesses selling unproven stem cell interventions are presenting themselves as engaging in research activities and how these messages are interpreted, reframed and redistributed by potential customers.

\section{Materials \& methods}

Our aim was to examine crowdfunding campaigns raising money for individuals seeking unproven stem cell interventions. To achieve this objective, we identified companies selling these services from a database of 351 US-based businesses engaging in direct-to-consumer advertising of unproven stem cell interventions. Developed by Turner and Knoepfler [12], the database contains company names, clinic locations, website addresses (URLs) and information about advertised cell types and indications purportedly treated with stem cells. This dataset was selected because to date it provides the largest publicly available list of US companies selling unproven stem cell products. The name of each of these businesses, in part and in full, was inputted into the internal search engines used on the websites of GoFundMe and YouCaring, two of the leading crowdfunding platforms for medical expenses in North America. These results were then augmented by using the Google search engine to search each crowdfunding platform website for mentions of each clinic name (e.g., site: gofundme.com [clinic name]). Each identified campaign was then individually reviewed to determine whether it raised funds for stem cell treatment at one of the 351 clinics identified by Turner and Knoepfler. These searches returned 408 total results (GoFundMe: $\mathrm{n}=358$; YouCaring: $\mathrm{n}=50$ ).

The text of each of these 408 crowdfunding campaigns was reviewed by the first author for any mention of clinical research reportedly conducted by US-based businesses involved in direct-to-consumer marketing of putative stem cell interventions and purporting to offer stem cell procedures in the context of studies or trials. This review included a search for claims concerning the administration of stem cells in the context of 'trials', 'studies', 'research', 'clinical research', 'experimentation', 'patient-funded studies' and any related terms. This search identified 78 campaigns discussing clinical research (GoFundMe: $n=72$; YouCaring: $n=6$ ). The relevant text of each of these campaigns was then copied into a document that was reviewed independently by each of the authors. Each author reviewed this document in its entirety and noted common themes found in this text. The authors compared their observations, noted wide agreement in these observations, and identified three overarching themes regarding representations of clinical research in crowdfunding campaigns for unproven stem cell interventions (with some campaigns matching 
two or more themes). The three identified themes are: research as a signifier of scientific credibility $(\mathrm{n}=56,71.8 \%)$; the unproven, experimental nature of stem cell interventions as a rationale for why they are not covered by public or private health insurance providers $(\mathrm{n}=40,51.3 \%)$; and engaging in research and developing new therapies as a means of contributing to the advancement of science and biomedical knowledge $(n=21,26.9 \%)$.

\section{Results}

The 78 identified campaigns requested US $\$ 1,663,243$ and raised US $\$ 403,507$. In total, 3717 donors contributed to these campaigns, with an average donation size of $\$ 108.56$. The most common underlying medical conditions motivating these campaigns were multiple sclerosis $(n=34,43.6 \%)$, chronic obstructive pulmonary disease $(n=9$, $11.5 \%)$, diseases of the eye $(n=6,7.7 \%)$, joint disease $(n=4,5.1 \%)$ and Parkinson's disease $(n=4,5.1 \%)$. Of the 37 campaigns specifying the source of the stem cells for the proposed intervention, $32.4 \%(n=12)$ stated that they were autologous, $48.9 \%(n=18)$ autologous adipose, $10.8 \%(n=4)$ autologous bone marrow, $5.4 \%(n=2)$ unspecified bone marrow and $2.7 \%(\mathrm{n}=1)$ donor tissue. Among the 408 crowdfunding campaigns identified as seeking treatment at one of the clinics identified by Turner and Knoepfler [12], several businesses dominated these campaigns. These companies included Stemgenex $(n=142,34.8 \%)$ and the Lung Institute $(n=139,34.1 \%)$. Campaigns for funding to access stem cell procedures advertised by Stemgenex were even more highly represented among the 78 campaigns discussing clinical research $(n=35,44.9 \%)$ while campaigns seeking donations to fund stem cell interventions provided by the Lung Institute were seen less frequently $(\mathrm{n}=13,16.7 \%)$. Other commonly mentioned businesses included MD Stem Cell $(n=5,6.4 \%)$ and the Stem Cell Rejuvenation Center $(n=4,5.1 \%)$.

\section{Research as a signifier of scientific credibility}

In these campaigns, the treatments being sought were frequently described as a form of research or as part of a study. For example, one company was described as "a stem cell research facility that has been doing studies for 10 years with stem cells for a myriad of different ailments". In some cases, references to study participation were subtle, as with frequent links to information from the Stemgenex website where multiple html addresses include language referencing studies (e.g., stemgenex.com/studies/multiple-sclerosis-stem-cell-studies/ and stemgenex.com/studies/rheumatoid-arthritis-stem-cell-studies/), or descriptions of treatments as 'experimental', 'ground-breaking', or 'cutting edge'. In other cases, connections between these treatments and clinical research were more direct, as in campaigns seeking funds for 'stem cell research' or, in another case, a 'clinical trial stem cell transplant'. These businesses and their staff members were also linked with research activities, as with one company described as doing 'clinical research' and another as a 'research clinic'. References to company employees were also used to link particular facilities to research activities, as when staff's research credentials were listed and a lead physician was described as performing 'clinical research studies'. In one atypical but notable case, discovering that claims of a clinical research connection were the subject of litigation led a campaigner to question the legitimacy of an advertised stem cell treatment. In that case, the campaigner changed her plans to raise funds to purchase services at a particular clinic after discovering that it was being sued for allegedly manipulative marketing practices and 'based on a lack of clinically accepted trials and evidence of success'.

These campaigns also used references to specific US government research institutions and funding agencies to associate the campaign with research. For example, one campaign made the case for donations to fund treatment provided in 'government-approved clinical trials'. Linkages to government research institutions took place most often through references to the NIH. Registration with the NIH's ClinicalTrials. gov website was referenced in seven campaigns, including through links to registered studies or search results listing specific clinics. In some cases, these links clearly implied support from the NIH, as with the claim that a clinic was 'doing treatments approved by the National Institute [sic] of Health' or, in another campaign, that a clinic 'sponsors its stem cell clinical studies through the National Institutes of Health'. In other cases, more general statements that treatments provided in studies were 'registered with the National Institutes of Health' were used. In some instances, the significance of this registration was overstated, as in one campaign that linked to the ClinicalTrials.gov website and stated that the procedure was 'funded by the NIH'. In fact, this study lists only the business, MD Stem Cells, as a sponsor on the ClinicalTrials.gov page for the study [35]. Similar connections were made to the state-funded California Institute for Regenerative Medicine (CIRM), as in a campaign describing 'a Phase I/II clinical trial' being undertaken by 'CIRM-funded researchers'. Links were also made to the FDA (mentioned in 24 campaigns), which licenses cell-based medical products for use following safety and efficacy reviews. This was demonstrated, for example, through reference to a doctor as the only person 'FDA approved in the USA to perform this type of stem cell procedure'. Crucially, such 
claims are inaccurate given that while the FDA is legally empowered to provide premarketing authorization for cellular therapies, it does not approve particular healthcare practitioners' delivery of such products.

\section{Labeling \& insurance coverage}

Crowdfunding campaigns that described their intended treatment as connected to medical research often portrayed this treatment as falling in a special experimental category, distinct from more established, mainstream treatment. The categorization of interventions as experimental was in some cases disputed, as with one campaigner that wrote "These are not experimental treatments. They are tried and backed by many studies". In other cases, the status of the treatment as 'experimental' was interpreted as consistent with the treatment as having been demonstrated to be effective. For example, one campaign indicated that the treatment was still in the FDA 'approval stages' but that 'medical research has proven over a long period of time that stem cell treatments do work'. In some cases, the medical establishment and pharmaceutical companies were seen to be engaged in a collective effort to continue labeling the interventions provided by these clinics as experimental research rather than proven treatment. One campaign described these stem cell interventions as threatening " a trillion dollar industry with Healing Patients rather than keeping them on a lifetime of drugs and medical devices invented to keep them sick". Similarly, another campaign accused the 'medical industry' of the "lobbying of our political establishment" to keep these treatments labeled as experimental interventions lacking FDA approval.

The experimental status of stem cell interventions marketed by these businesses was often used as a justification for why these fundraising campaigns were necessary. This was due to repeated statements that both public insurers and providers of private health insurance were unwilling to pay for research participation and provide insurance coverage for experimental stem cell products. The key point, as one representative campaign put it, is that "As long as the FDA calls these procedures 'Experimental' the Insurance companies will do the same". This point was typically applied to private insurers in the USA, but was in some cases used in relation to public insurers as well. As one campaign launched by a Canadian patient noted, financial support was needed because the public insurance system would not pay for treatment: "there is no OHIP [Ontario Health Insurance Plan] or medical coverage here in Canada for a stem cell transplant because it's still considered experimental research". Similarly, the public US Veterans Affairs administration was stated as unwilling to pay for a stem cell intervention, "claiming that the procedure is 'Experimental' and 'Research'".

Put more generally, as long as stem cell interventions remain at the research stage and are not covered by health insurance providers, crowdfunding for this care was depicted in these campaigns as remaining necessary. In one case, a campaign distinguished between the current landscape of 'patient-supported trials' and insurance company-funded treatment, hoping that insurance companies would soon 'get on board' with funding these trials. In this vein, one campaign drew a parallel between an experimental stem cell intervention and bone marrow transplants now proven to be effective for treatment of leukemia, multiple myeloma and other indications: "People paid THOUSANDS of dollars privately for that to save their life because the FDA didn't approve the procedure. That's exactly where stem cell transplants are now... fighting for FDA approval". These campaigns often expressed hope that the treatments being sought would soon transition from experimental to 'proven' status, so that insurance companies would begin paying for the treatment. For one campaigner, this transition was particularly desirable as yearly treatment was needed. In many cases, waiting for final FDA approval and insurance coverage was not seen as an option given the severity of the designated recipient's medical need. For example, one recipient who was told that "stem cell treatment will not be FDA approved for at least three more years", she 'simply does not have "three years, or more", to wait'.

\section{Contributing to research}

Claims that these campaigns were raising funds to allow the recipient to take part in stem cell studies were used to motivate giving on the grounds that donations would advance credible scientific research intended to develop safe and effective therapies for particular clinical indications. These campaigners saw themselves as making a positive contribution to science through their participation in these studies, giving them the opportunity 'to help with research'. This conviction was stated explicitly in several cases, positioning the treatment as part of a clinical trial that would directly contribute to FDA approval of the treatment: "My progress will be followed and studied by Stemgenex, and the results will be shared with the FDA in the fight for approval". In one case, a campaign presented the recipient as hoping to take part in a clinical trial with uncertain results and, for this reason, presented her as self-sacrificing for the good of others: "It takes courageous people like Jan to participate in trials, such as this one, in order to help future MS patients". Similarly, another campaigner put her desire for financial assistance not in 
self-interested terms but as a means of helping others, as "The more people that get into this type of clinical study, the sooner we can find either a cure for MS or at least a way to stop the progression". For another recipient, one justification for taking part 'in effect part of a clinical trial upon which the FDA may someday decide that stem cell therapy is fully approved' to treat Parkinson's disease was that, even if he himself was not cured of the disease, participation in clinical research would "give some meaning to my suffering".

These campaigns also argued that their donations would directly contribute to scientific research, assist in proving the efficacy of these treatments, and speed the process of obtaining regulatory approval of these stem cell treatments. Helping the recipient gain access to treatment was thus presented as simultaneously helping the goals of research and, potentially, many people suffering and in need: "So know that when you help me, you will also be helping the study on Stem Cells \& the improvement they have on MS!!!! YEAH for you \& All those future patients!! . . YOU WILL BE REALLY HELPING THOUSANDS MORE". In other cases, the research aims of the treatment were highlighted such that the treatment goals of the recipient were nearly invisible. In these cases, the appeal to donors was not to aid treatment but to aid research: "Donating to this regenerative research may bring us closer to a cure for MS as well". In one instance, the campaigner noted that if the treatment were proven to work, insurance companies would begin funding the treatment and 'people [sic] lives can be improved for the better'; as a result, "You will be supporting a very important program that will help thousands of other people suffering kidney failure here in America, who could benefit from stem cell treatment". An adversarial stance toward insurance companies and the medical sector for their failure to fund these interventions was in some cases also reflected in these calls to aid research; for example, some campaigns presented the call to donate as a way to create overwhelming evidence of the efficacy of these treatments and 'force the FDA and Big Pharma to recognize they are the problem and not the solutions' in a battle of 'America vs the FDA'.

\section{Discussion}

As these findings show, crowdfunding campaigns follow the example of businesses selling purported stem cell treatments in using research as a persuasive indication of scientific credibility. Demonstrating the legitimacy of these treatments is important to crowdfunding campaigners as they must show potential donors that their money will be put to effective use and has the potential to improve the health of the recipient. As with stem cell businesses, these campaigners reference study participation and government research and funding agencies to build credibility. However, in some cases these campaigns go beyond subtle linkages to research and government institutions found in stem cell businesses' marketing materials; as demonstrated above, many crowdfunding campaigns include unfounded claims around regulatory approval, scientific legitimacy and research activities.

In some campaigns, insurers and government regulators were seen in an adversarial light, labeling treatments as unproven or experimental when, the campaigners claimed, their efficacy was clear. In many of these cases, the campaigners made questionable efficacy claims and by doing so repeated and amplified the marketing messages of stem cell businesses. As insurance funding for these treatments is tied to regulatory approval and shedding of the 'experimental' label, these campaigners justified seeking funding from their friends and families based on their need for these treatments and inability to wait for regulators being finally convinced of these treatments' efficacy.

Because insurance funding for these treatments was seen as tied to proving their efficacy through scientific studies, these campaigns motivated giving by arguing that their participation in these 'trials' would advance science and hasten regulatory approval. Given the great good that would come from new stem cell treatments for all those suffering from what would now be treatable diseases, many campaigns argued, the campaign's targeted recipient was not simply a passive receiver of charity but actively engaged in making their own personal sacrifice for the good of others through trial participation. Similarly, those considering donating to these campaigns could see themselves as not just supporting the individual campaign's recipient but also the entire collective enterprise of stem cell research. Thus, these unsupported claims of the likely scientific benefits of pay-to-participate clinical trials became a substantial part of the appeal to donate.

Critics of businesses advertising unproven stem cell interventions have argued that references to clinical trials and links to government regulatory and funding agencies such as ClinicalTrials.gov are likely to mislead those considering purchasing these services [27]. This concern is supported by these findings in that a significant number of medical crowdfunding campaigns misleadingly communicate that the recipient will be participating in clinical research that will spur regulatory approval of these treatments and help others. As those analyzing these businesses' marketing materials have warned, the ability to register their trials on ClinicalTrials.gov and to use other tokens of legitimacy has clearly positively influenced potential customers as to the legitimacy of these products. Although 
campaigners have an incentive to exaggerate these misleading claims in order to build their case for donations, nonetheless they clearly demonstrate a belief that these products are connected to legitimate research activities that spurs their interest in these putative stem cell products. This is concerning in itself as it suggests that consumers are not making fully informed decisions about whether to purchase stem cell treatments. Moreover, it is problematic that, because of the nature of crowdfunding, these claims are broadcast to and shared with a much wider audience than the actual donor base through social media shares on Facebook, Twitter and other platforms.

As a result, calls for these businesses to stop making misleading claims about the scientific validity of their products and relationships with government regulatory and funding bodies are supported by this study. Medical crowdfunding campaigns frequently quote directly from these businesses' marketing materials and include links to their websites to support their claims of the scientific validity of these treatments. Thus, not only is there a clear causal connection between the existence of these misleading claims and the amplification of these claims in crowdfunding campaigns and social media, but the removal of these claims would clearly reduce the presence of misinformation about, for example, the likelihood of pay-to-participate trials leading to regulatory approval of these treatments. Given these findings, businesses making these claims cannot reasonably deny that many seeking their services are internalizing and spreading misinformation. Whether this spread of misinformation is deliberate or not on the part of these businesses, they have a responsibility to address this impact.

Based on these findings, the NIH, FDA and other scientific regulatory and granting agencies should be concerned about their names, reputations and programs being co-opted to misrepresent the nature of what these clinics are doing. Inaction by these agencies risks enabling the spreading of misinformation we have observed in crowdfunding campaigns given the role that association with research activity plays in encouraging funding the purchase of unproven stem cell interventions. Thus, these agencies have an obligation to intervene to counteract statements by clinics that mislead consumers as to the nature of their activities. This study demonstrates that references to the $\mathrm{NIH}$ and FDA serve as tokens of legitimacy for those seeking funding to purchase unproven stem cell interventions. One practical response for the NIH would be to better screen clinical studies submitted to the NIH-administered website, ClinicalTrials.gov. Although ClinicalTrials.gov now has on its home page a disclaimer that notes studies registered on ClinicalTrials.gov have not been reviewed and approved by the NIH, this website is a trusted resource for patients and their loved ones. To maintain ClinicalTrials.gov's standing as a reputable and trustworthy resource for identifying credible clinical trials, the NIH should play a role in vetting studies registered and made publicly accessible in the database. Likewise, the FDA should take steps to prevent businesses from claiming the stem cell interventions they promote are approved or permitted by the FDA, if the FDA has in fact not granted such approval or permission. Though these recommendations are limited to US agencies, government bodies in other countries should take similar steps if businesses selling unlicensed stem cell interventions make claims about government bodies that are inaccurate but serve to lend credibility to companies' marketing practices and commercial activities.

When determining which businesses to investigate, we suggest that regulatory and funding agencies should place a high priority on businesses making misleading marketing claims about conducting 'trials' and 'studies' and whose businesses are disproportionately represented in crowdfunding campaigns echoing these unsupported claims. That is, the findings presented here can be used to augment existing research on the claims made on these businesses' websites and other advertising $[10,36,37]$ to inform decisions as to which businesses are having a disproportionate impact on misleading potential customers as to the scientific validity and research potential of their services. As this study shows, the businesses identified by Turner and Knoepfler [12] are not evenly represented in crowdfunding campaigns. Rather, there are a few businesses that play a very large role in broadcasting the unsupported messaging found in crowdfunding campaigns. Additional and continuing reviews of medical crowdfunding campaigns could help to guide enforcement by identifying and tracking patterns in which businesses are encouraging misleading statements by their potential customers. Specifically, additional reviews of crowdfunding campaigns could be conducted as new businesses making misleading marketing claims are identified and ongoing reviews could identify new trends in how their potential customers are interpreting and broadcasting these claims.

\section{Limitation}

The crowdfunding campaigns reviewed were all for services at US-based clinics. Although some campaigns were for non-US residents, all of these campaigns represent the impacts of marketing messages taking place in the context of the USA. Moreover, the crowdfunding platforms reviewed predominantly host English-language campaigns. As a result, some aspects of our findings may not be applicable to crowdfunding for interventions outside of the USA and other English-speaking countries. We limited our search to campaigns referencing one of the 351 
US-based businesses marketing putative stem cell treatments directly to consumers [12] in order to focus on campaigns to purchase unproven stem cell interventions. As a result, crowdfunding campaigns for unproven stem cell interventions that did not mention these businesses were not reflected in our analysis.

\section{Conclusion}

Our review of crowdfunding campaigns raising money to purchase putative stem cell treatments offered by US businesses demonstrates that these campaigners internalize, repeat and exaggerate claims found in these businesses' marketing materials. Specifically, these campaigns repeat, exaggerate and broadcast to a wide audience claims that these businesses are engaged in legitimate scientific research. Association of these treatments with scientific research helps to bring credibility to these businesses, and their potential customers often view purchasing these services as a way of advancing science and helping progress toward finding new cures for their illnesses as well as forcing public and private insurers to fund them. These findings provide evidence in support of existing concerns regarding misleading statements in these businesses' marketing materials, the co-opting of scientific funding and regulatory agencies to legitimize their services, and a failure of their potential customers to make fully informed decisions regarding their purchase of these treatments. Given that crowdfunding broadcasts these misleading statements to a wide audience, concerns with the full impacts of these marketing materials may actually be greatly understated. Thus, the case for regulatory bodies intervening to limit and counteract misleading marketing tactics is well supported by this study. Simply put, patients and research subjects require accurate information to make informed choices.

These crowdfunding campaigns regularly demonstrated confusion over and exaggeration of the role and impact of legitimate stem cell scientific research. They provide a cautionary lesson to all practices that combine the potential for therapeutic responses with research activities. In the case of pay-to-participate research trials, this study shows a potential for a 'research misconception' where potential participants misconstrue the likely scientific impact and legitimacy of their participation. Medical crowdfunding campaigns provide a wealth of information on the experience of would-be participants in these programs that can help to provide empirical support for the more speculative concerns about the expansion of access to research activities outside of well-regulated clinical trials. Continued monitoring of these campaigns can help to reveal developing trends in the pay-to-participate and rightto-try clinical trial arenas and help to determine whether the problems highlighted in this study are confined to the market for putative stem cell treatments or more widely spread across patients accessing unproven or experimental interventions.

\section{Future perspective}

These and other concerns with the crowdfunding industry will likely lead to increased pressure on crowdfunding platforms to limit and shape the content of the campaigns they host. These platforms have generally been hesitant to provide such oversight but have been willing to remove campaigns that violate their community standards, are fraudulent, or are otherwise controversial [38]. These interventions could potentially be extended to campaigns with clearly fraudulent claims about research participation or medical efficacy. More modestly, these platforms could be encouraged to provide information and warnings to campaigners and potential donors that claims in these campaigns are not vetted and that those regarding unproven stem cell interventions are particularly unreliable.

Continuous future efforts will be needed to educate potential consumers about these products. Journalists, scientists, medical societies, international research bodies and national and international health agencies have all been targeted by calls to educate the public about the efficacy and safety of stem cell treatments and best practices in stem cell research and, in many cases, have responded to these calls [25,39-41]. The findings presented here can help to better shape and direct these efforts by identifying marketing messages and specific businesses that have proven to be most influential in encouraging individuals to purchase putative stem cell treatments. By identifying these messages, public health advocates can craft responses to specific claims and businesses and seek to place these responses in venues that potential customers are most likely to see. Moreover, these stakeholders can use these findings to seek cooperation from the crowdfunding industry to develop interventions through their platforms to counteract the misinformation that is being spread to a wide audience through medical crowdfunding.

Efforts to speed access to unproven medical treatments have been increasing in the USA and elsewhere in the name of deregulation, autonomy and compassion for terminally ill patients. Although there are credible arguments in favor of increasing patient access to medical interventions that are still undergoing testing, ethicists and policy makers have warned that unscrupulous businesses may take advantage of such deregulation to market their products 
directly to consumers under the guise of a 'right-to-try'. Even well-intentioned companies and researchers may have a difficult time conveying to interested patients the likely efficacy of these products $[25,42]$. As our exploration of crowdfunding campaigns for unproven stem cell interventions shows, those seeking these products are influenced by scientific- and research-based markers of legitimacy, prone to overstating the proven efficacy of these products, and likely to misunderstand their role in the process of legitimate scientific research. Just as researchers should be wary of presenting their research activities as proven treatment in order to avoid a 'therapeutic misconception' by research participants, those offering unproven interventions on a pay-to-participate or right-to-try model will need to be wary of promoting a 'research misconception' by their customers.

\section{Summary points}

- There is now a large global marketplace composed of businesses selling unproven stem cell interventions. Early empirical studies found that such businesses were based in China, India, Russia and the Ukraine. Recent research has documented the proliferation of such clinics in Australia, Japan and the USA.

- Business use variety of marketing techniques and 'tokens of legitimacy' to sell unproven stem cell interventions. Strategies include advertising patient-funded stem cell studies, marketing studies as approved by oversight bodies, and registering studies on ClinicalTrials.gov.

- Such studies have been subjected to substantial criticism for in many instances failing to comply with ethical, scientific and legal standards.

- To understand how clinics' representations about providing stem cell products within clinical studies are interpreted by patients and prospective clients, this study examined crowdfunding campaigns for unproven stem cell interventions.

- The study reviewed campaigns on two crowdfunding websites, GoFundMe and YouCaring.

Materials \& methods

- Searches yielded a total of 408 crowdfunding campaigns involving individuals seeking donations to finance purchase of stem cell interventions provided at US clinics.

- These campaigns were identified by searching for campaigns associated with 351 US businesses.

- In total, 78 of the 408 campaigns stated that stem cell interventions were available within patient-funded studies.

- Careful study of these campaigns resulted in the identification of three overarching themes. These themes are: research as a sign of scientific legitimacy; the experimental nature of stem cell interventions explains why such procedures are not insured; and participation in research provides a means by which individuals believe they can contribute to the advancement of knowledge.

Results

- Several US businesses were repeatedly mentioned by campaigns seeking funding to participate in stem cell studies.

- These campaigns indicated that clients view stem cell studies as a signifier of scientific credibility.

- Campaigns also emphasized that experimental nature of stem cell research meant that study-related costs are not covered by insurance providers.

- Many individuals seeking funding to participate in stem cell studies claimed that such research will help advance biomedical knowledge.

Discussion

- Claims made in crowdfunding campaigns help spread the tokens of legitimacy businesses use to market unproven stem cell interventions.

- These tokens have persuasive effects and appear to inform individuals' decisions to seek procedures marketed by particular businesses.

- Prospective clients draw upon these marketing claims when trying to convince individuals to help fund their stem cell procedures.

- The NIH, US FDA and other bodies should be concerned about how their names and reputations are used by businesses selling unapproved stem cell interventions. Misleading representations can play a significant role in leading individuals to provide donations for such procedures.

- Regulatory bodies should prioritize investigating businesses that make misleading claims about conducting stem cell studies and also are disproportionately represented in crowdfunding campaigns.

Limitation

- The study was limited to English-language campaigns for services provided by US-based clinics.

Conclusion

- Crowdfunding campaigners internalize and help spread claims businesses make about providing stem cell interventions within pay-to-participate studies. Claims about these studies often are inaccurate, whether made by businesses themselves or by clients using crowdfunding sites to solicit donations. 


\section{Financial \& competing interests disclosure}

The authors have no relevant affiliations or financial involvement with any organization or entity with a financial interest in or financial conflict with the subject matter or materials discussed in the manuscript. This includes employment, consultancies, honoraria, stock ownership or options, expert testimony, grants or patents received or pending, or royalties.

No writing assistance was utilized in the production of this manuscript.

\section{Ethical conduct of research}

The authors state that they have obtained appropriate institutional review board approval or have followed the principles outlined in the Declaration of Helsinki for all human or animal experimental investigations.

\section{Open access}

This work is licensed under the Attribution-NonCommercial-NoDerivatives 4.0 Unported License. To view a copy of this license, visit http://creativecommons.org/licenses/by-nc-nd/4.0/

\section{References}

1. Cohen CB, Cohen PJ. International stem cell tourism and the need for effective regulation. Part I: stem cell tourism in Russia and India: clinical research, innovative treatment, or unproven hype? Kennedy Inst. Ethics J. 20(1), 27-49 (2010).

2. Cohen CB, Cohen PJ. International stem cell tourism and the need for effective regulation. Part II: developing sound oversight measures and effective patient support. Kennedy Inst. Ethics J. 20(3), 207-230 (2010).

3. Lau D, Ogbogu U, Taylor B, Stafinski T, Menon D, Caulfield T. Stem cell clinics online: the direct-to-consumer portrayal of stem cell medicine. Cell Stem Cell 3(6), 591-594 (2008).

4. Ogbogu U, Rachul C, Caulfield T. Reassessing direct-to-consumer portrayals of unproven stem cell therapies: is it getting better? Regen. Med. 8(3), 361-369 (2013).

5. Ryan KA, Sanders AN, Wang DD, Levine AD. Tracking the rise of stem cell tourism. Regen. Med. 5(1), 27-33 (2010).

6. Kiatpongsan S, Sipp D. Monitoring and regulating offshore stem cell clinics. Science 323, 1564-1565 (2009).

7. Caulfield T, Zarzeczny A, McCormick J et al. The stem cell research environment: a patchwork of patchworks. Stem Cell Rev. 5(2), 82-88 (2009).

8. Caulfield T, Zarzeczny A, McCormick J et al. International stem cell environments: a world of difference. Nat. Rep. Stem Cells 5(2), 82-88 (2009).

9. Fujita M, Hatta T, Ozeki R, Akabayashi A. The current status of clinics providing private practice cell therapy in Japan. Regen. Med. 11(1), 23-32 (2016).

10. Munsie M, Lysaght T, Hendl T, Tan HL, Kerridge I, Stewart C. Open for business: a comparative study of websites selling autologous stem cells in Australia and Japan. Regen. Med. 12(7), 777-790 (2017).

11. Berger I, Ahmad A, Bansal A, Kapoor T, Sipp D, Rasko JE. Global distribution of businesses marketing stem cell-based interventions. Cell Stem Cell 19(2), 158-162 (2016).

12. Turner L, Knoepfler P. Selling stem cells in the USA: assessing the direct-to-consumer industry. Cell Stem Cell 19(2), 154-157 (2016).

13. Kuriyan A, Albini T, Flynn H Jr. The growing “stem cell clinic” problem. Am. J. Ophthalmol. 177, xix-xx (2017).

14. Turner LG. US clinics marketing unproven and unlicensed adipose-derived autologous stem cell interventions. Regen. Med. 10(4), 397-402 (2015).

15. Turner L. US stem cell clinics, patient safety, and the FDA. Trends Mol. Med. 21(5), 271-273 (2015).

16. Sipp D. The malignant niche: safe spaces for toxic stem cell marketing. NPJ Regen. Med. 2(1), 1-4 (2017).

17. Sipp D, McCabe C, Rasko J. Show drugs work before selling them. Nature 543(7644), 174-175 (2017).

18. Ledford H. Boom in unproven cell therapies intensifies regulatory debate. Nature 537(7619), 148 (2016).

19. Aldous P. An experiment that blinded three women unearths the murky world of stem cell clinics. BuzzFeed News (2017). www.buzzfeed.com/peteraldhous/stem-cell-tragedy-in-florida?utm_term=.ui5jb8kEE0\#.ud0M854AAw

20. Marks PW, Witten CM, Califf RM. Clarifying stem-cell therapy's benefits and risks. N. Engl. J. Med. 376(11), 1007-1009 (2016).

21. Arnold C. Texas stem cell rules may impede clinical research. The Lancet 379, 1776 (2012).

22. Drabiak-Syed K. Challenging the FDA's authority to regulate autologous adult stem cells for therapeutic use: Celltex Therapeutics' partnership with RNL Bio, substantial medical risks, and the implications of United States v. Regenerative Sciences. Health Matrix Clevel. 23(2), 493-535 (2013).

23. McFarling U. FDA moves to crack down on unproven stem cell therapies. STAT (2016). www.statnews.com/2016/02/08/fda-crackdown-stem-cell-clinics/ 
24. Sipp D. Direct-to-consumer stem cell marketing and regulatory responses. Stem Cells Transl. Med. 2(9), 638-640 (2013).

25. Sipp D, Caulfield T, Kaye J et al. Marketing of unproven stem cell-based interventions: a call to action. Sci. Transl. Med. 9(397), 1-5 (2017).

26. Bianco P, Sipp D. Regulation: sell help not hope. Nature 510(7505), 336-337 (2014).

27. Sipp D. Stem cell stratagems in alternative medicine. Regen. Med. 6(3), 407-414 (2011).

28. Turner L. ClinicalTrials.gov, stem cells and 'pay-to-participate' clinical studies. Regen. Med. 12(6), 705-719 (2017).

29. Sipp D. Pay-to-participate funding schemes in human cell and tissue clinical studies. Regen. Med. 7(Suppl. 6), 105-111 (2012).

30. Wenner D, Kimmelman J, London A. Patient-Funded Trials: Opportunity or Liability? Cell Stem Cell 17, 135-137 (2015).

31. Harris A. GoFundMe keeps gobbling up competitors, says it’s "very good for the market". Fast Company (2018). www.fastcompany.com/40554199/gof undme-keeps-gobbling-up-competitors-says-its-very-good-for-the-market

32. Jopson B. Why are so many Americans crowdfunding their healthcare? Financial Times (2018). www.ft.com/content/b99a81be-f591-11e7-88f7-5465a6cela00

33. Marche S. Go fund yourself. Mother Jones (2018). www.ft.com/content/b99a81be-f591-11e7-88f7-5465a6ce1a00

34. Berliner LS, Kenworthy NJ. Producing a worthy illness: personal crowdfunding amidst financial crisis. Soc. Sci. Med. 187, 233-242 (2017).

35. MD Stem Cells. Stem cell ophthalmology treatment study (SCOTS) (2018). https://clinicaltrials.gov/ct2/show/NCT01920867

36. Connolly R, O’Brien T, Flaherty G. Stem cell tourism - a web-based analysis of clinical services available to international travellers. Travel Med. Infect. Dis. 12(6), 695-701 (2014).

37. Rachul C, Rasko JE, Caulfield T. Implicit hype? Representations of platelet-rich plasma in the news media. PLoS ONE 12(8), 1-9 (2017).

38. Snyder J. Crowdfunding for medical care: ethical issues in an emerging health care funding practice. Hastings Cent. Rep. 46(6), 36-42 (2016).

39. Zarzeczny A, McNutt K. Wicked policy issues in regenerative medicine and the need to explore new avenues for public engagement. Regen. Med. 12(7), 749-752 (2017).

40. Weiss DJ, Turner L, Levine AD, Ikonomou L. Medical societies, patient education initiatives, public debate and marketing of unproven stem cell interventions. Cytotherapy 20(2), 165-168 (2018).

41. Knoepfler P, Turner L. The FDA and the US direct-to-consumer marketplace for stem cell interventions: a temporal analysis. Regen. Med. 13(1), 19-27 (2018).

42. Bateman-House A, Kimberly L, Redman B, Dubler N, Caplan A. Right-to-try laws: hope, hype, and unintended consequences. Ann. Intern. Med. 163(10), 796-797 (2015). 